\title{
¿Ciudadanía versus diversidad y marginación?
}

DIANA GUILLÉN *

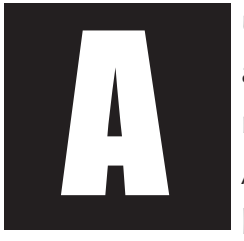

un lustro de haber dejado atrás el siglo $X X$, quienes aprendimos a caminar durante su segunda mitad, y además nacimos en alguno de los países de los que emerge Nuestra América, hemos desarrollado sentimientos encontrados hacia la democracia. Dependiendo de historias personales, sociales e incluso territoriales, transitamos de manera intermitente entre la esperanza y la frustración y más de una vez nos preguntamos lo que significa construir intercambios políticos basados en principios democráticos.

Hay sin duda posiciones variadas al respecto y mientras para algunos se trata de la única senda posible a seguir, otros más cuestionan sus implicaciones y, sobre todo, sus alcances. En lugar de argumentar a favor o en contra, me interesa reflexionar sobre lo que significa para un buen número de latinoamericanos, la alternativa de transitar hacia un intercambio democrático, en medio de tendencias excluyentes que reducen e incluso eliminan el sentido homogeneizador de una categoría como la de ciudadano.

\footnotetext{
* Doctora en en Estudios Latinoamericanos, desde 1984 es profesora-investigadora de tiempo completo en el Instituto Mora (actualmente se encuentra adscrita al área de Sociología Política y Económica) y profesora de asignatura en la Facultad de Ciencias Políticas y Sociales de la Universidad Nacional Autónoma de México (UNAM).
} 


\section{Cifras que ilustran...}

La serie de inequidades que han acompañado el andar de las sociedades latinoamericanas, rebasan el plano individual; son producto de formas históricamente construidas y reflejan lógicas de producción e intercambio encaminadas a la concentración económica.

Se trata de un escenario que se ha ido armando en el largo plazo y dentro del cual las semillas polarizantes han encontrado suelo fértil para germinar: el decil más rico de la población se queda con el $48 \%$ del ingreso total, mientras que el decil más pobre sólo recibe el 1,6\% (en las naciones industrializadas el decil superior recibe el 29,1\% mientras que el decil inferior recibe el 2,5\%). La inequidad en el país menos desigual de la región (Uruguay) es superior respecto al país más desigual de Europa oriental y los países industrializados. En promedio, la desigualdad del ingreso ha tendido a empeorar aunque las experiencias son variadas; algunos países con relativa igualdad, como Argentina, Uruguay y Venezuela, han incrementado su desigualdad interna. Se supone que Brasil (el país con mayor desigualdad de la región) y México experimentaron una mejora, pero las brechas siguen siendo abismales (véase Ferranti, 2004).

Los niveles de pobreza con los que América Latina arrancó el siglo XXI, van más allá de la región. Si pensamos en cifras mundiales, encontraremos que de un total de 6000 millones de habitantes, en el Informe del Banco Mundial (BM) para el año 2001 se reportaba que 2800 millones casi la mitad — vivían con menos de US\$2 diarios, y 1200 millones —una quinta parte- con menos de US\$1. En los países ricos, los niños que no llegaban a cumplir cinco años eran menos de uno de cada 100, mientras que en los países más pobres una quinta parte de los niños no alcanzaba esa edad. Asimismo, mientras que en los países ricos menos del 5\% de todos los niños menores de cinco años sufría de malnutrición, en las naciones pobres la proporción era de hasta el 50\%. El ingreso promedio en los 20 
países más ricos era 37 veces mayor que el de las 20 naciones más pobres; esta brecha se había duplicado en los 40 años previos (véase Banco Mundial, 2000, pp. 3-4).

Las acciones encaminadas a revertir los efectos de tal disparidad, han sido insuficientes. A un lustro de haber hecho públicas las cifras mencionadas, enfatizando el tema de la "lucha contra la pobreza", las estrategias impulsadas por el BM y otros organismos internacionales no han logrado su cometido. ${ }^{1}$ Los magros resultados de una política que en lugar de atacar las causas, busca paliar los efectos, se reflejan en el caso de América Latina en una profundización de las desigualdades.

De acuerdo a estimaciones de la CEPAL, en 2002 los índices de pobreza se habían estancado en la región y el número de latinoamericanos que la padecía alcanzó los 220 millones de personas, de los cuales 95 millones eran indigentes, lo que representaba el $43,4 \%$ y $18,8 \%$ de la población respectivamente (véase Panorama, 2003).

Las proyecciones hasta 2004, basadas en el crecimiento económico de los países, registran para América Latina y el Caribe 222 millones de pobres, cerca de $42.9 \%$ de la población regional, y 96 millones (18.6\%) en estado de indigencia. La magnitud de esta última varía dependiendo del lugar: en Bolivia, Guatemala, Honduras, Nicaragua y Paraguay afecta a más del 30\% de la población; en Argentina, Colombia, El Salvador, Perú, Venezuela y República Dominicana fluctúa entre el $20 \%$ y el 24\%, mientras que en Brasil, Ecuador, México y Panamá va del 12\% al 19\%. Sólo en Chile, Costa Rica y Uruguay se calculan niveles de indigencia inferiores al 10\% (véase Machinea, 2005).

\footnotetext{
1 En 2002, se buscó la creación y fortalecimiento de instituciones que contribuyesen al desarrollo de los mercados (véase Banco Mundial, 2001); un año después se privilegiaron las cuestiones relativas al desarrollo sustentable (véase Banco Mundial, 2002) y en 2004 la idea fue extender el funcionamiento de lo servicios para cubrir a los más desprotegidos (véase Banco Mundial, 2003), y poner mayor énfasis en mejorar el clima de inversión (véase Banco Mundial, 2004).
} 
La brecha entre riquezas mayúsculas y pobrezas extremas, se vuelve particularmente clara cuando se analiza la situación de las minorías étnicas. Para la última década del siglo XX, en América Latina se calculaban entre 33 y 40 millones de indígenas, divididos en unos 400 grupos étnicos con su propio idioma, organización social, cosmovisión, y formas de producción. Casi el $90 \%$ de esta población, se concentra en cinco países Perú (27\%), México (26\%), Guatemala (15\%), Bolivia (12\%) y Ecuador (8\%) (véase Hopenhayn, 2001, p. 14). De ellos, en Bolivia y Guatemala más del 50\% del total de la población y casi el 75\% de la población indígena es pobre. Entre los indígenas de Ecuador, la pobreza se acerca al 87\% y alcanza 96\% en las sierras rurales. En México, la incidencia de la pobreza extrema en 2002 era 4.5 veces mayor en los municipios predominantemente indígenas en comparación a las no indígenas. Finalmente, en Perú, de todos los hogares pobres $43 \%$ son indígenas (véase Hall, s/f).

Uno se pregunta qué tipos de ciudadanía pueden construirse, cuando las referencias identitarias de numerosos núcleos sociales se gestan en la marginación. Más allá del status jurídico al que remite el concepto y de las obligaciones y derechos políticos que le son inherentes, todo ejercicio ciudadano requiere mecanismos que garanticen niveles mínimos de inclusión en la colectividad.

Para acceder a la ciudadanía plena, hay que ver más allá de las prerrogativas formales que permiten votar y ser votado. Se trata de un proceso histórico de construcción, cuya célula básica es el individuo, pero cuyos amarres fundamentales provienen de la sociedad. Sólo considerando ambas dimensiones, adquiere sentido el papel que dentro de los regímenes republicanos y democráticos se asigna a los ciudadanos.

\section{¿Ciudadanía versus diversidad y marginación?}

La igualdad que en el papel establece el modelo ciudadano, no basta para diluir las desigualdades estructurales que atraviesan a sociedades como 
las latinoamericanas. A lo largo del tiempo se han realizado conquistas que amplían el espectro de derechos individuales y sociales, ${ }^{2}$ pero estos últimos seguirán siendo insuficientes mientras la inequidad impere en la región.

Parte sustancial de dicha inequidad proviene de la polarización económica y de la marginación que ésta conlleva en los terrenos social y político, pero también se vincula con el no reconocimiento a la diversidad cultural e identitaria. El modelo de Estado-nación homogéneo parece rebasado por la historia y, sin embargo, la figura del ciudadano en tanto célula básica del mismo, se mantiene.

Hoy en día, el concepto de ciudadanía debe considerar la existencia de actores que intervienen en las escenas social y política, a partir de referentes culturales e identitarios particulares. El medio ambiente, la sexualidad, el género o a la etnicidad, son algunos de los ejes articuladores que han propiciado la emergencia de demandas específicas para ampliar los tres niveles a los que generalmente alude la idea ciudadana: participación, derechos y pertenencia.

La patria, como referente político-jurídico, libre de determinaciones etnoculturales y socio-económicas, se enfrenta a una realidad plagada de esas diferencias que pretende obviar (véase Bermudo, 2001). Desde tal perspectiva, para llevar a buen término sus tareas en tanto amalgama ideológica del Estado moderno, tendría que ampliar su espectro e incorporar y darle sentido a una diversidad que exige ser reconocida.

En realidad habría que hablar de múltiples diversidades que exigen ser reconocidas. En paisajes tan heterogéneos como los latinoamericanos, encontramos varias pistas en este sentido; además de las que se generan en economías altamente polarizadas, que, de paso, abren profundas brechas

\footnotetext{
2 T.H. Marshal asocia la ciudadanía a tres tipos de derechos adquiridos de manera acumulativa entre los siglos XVIII y XX: a) civiles (libertades y prerrogativas individuales), b) políticos (votar y ser votado), y c) sociales (que incluyen "un mínimo de bienestar económico" y el "vivir la vida de un ser civilizado conforme a estándares predominantes en la sociedad"). Véase Marshall, 1998, pp. 22-23.
} 
entre el acceso masivo a imágenes, símbolos y mensajes colectivos, y el acceso restringido al dinero y a los beneficios materiales (véase Hopenhayn, 1996), me interesan las que provienen de la asignatura pendiente que hasta ahora han representado los pueblos indígenas de la región.

El reconocimiento de pertenencia, la ampliación de derechos y la existencia de canales de participación política independientemente de la raza, el género, la riqueza o la escolaridad, son sin duda conquistas importantes. El problema es que a partir de esa equidad formal otorgada a los individuos, se limitan los derechos, la participación y la pertenencia tanto de minorías que colectivamente reivindican su capacidad autonómica, como de amplias capas de la población que se encuentran condenadas a vivir en la marginalidad.

Las prerrogativas legales que amparan el status ciudadano de los indígenas que habitan a lo largo del subcontinente, en la mayoría de los casos contrastan con su capacidad para ejercer éste último sin sacrificar una cultura (en el sentido amplio del término) y una identidad construidas en el largo plazo. Asimismo, tales prerrogativas esconden condiciones estructurales que impiden llevarlas a la práctica.

De acuerdo al estudio del BM sobre pobreza y desarrollo humano entre los pueblos indígenas de América Latina, estos últimos representan un $10 \%$ de la población de la región y son el grupo más desfavorecido. De las grandes tendencias que los autores detectan para la última década (19942004) destacan: a) se ha avanzado poco en la reducción de la pobreza entre los indígenas; b) los indígenas se recuperan más lentamente de las crisis económicas; c) la brecha de pobreza de los indígenas es más profunda y disminuyó más lentamente durante los años noventa; d) ser indígena aumenta la probabilidad de un individuo de ser pobre; e) los indígenas continúan teniendo menos años de educación; f) los indígenas, especialmente mujeres y niños, continúan teniendo menor acceso a servicios básicos de salud (véase Hall, s/f). 
Revisando algunos de los datos que se ofrecen para los países con mayor presencia indígena, descubrimos escenarios poco alentadores. En el caso de Bolivia, este sector representa un $62 \%$ de la población, y, en las áreas rurales, el $72 \%$ habla lenguas indígenas, comparado con un 36\% en las zonas urbanas. En 2002, las tasas de pobreza rural y urbana eran más altas entre la población indígena que entre la población no indígena (86\% comparado con $74 \%$ en las zonas rurales y $59 \%$ comparado con $47 \%$ en las zonas urbanas). Si bien para la población no indígena las tasas de extrema pobreza disminuyeron entre 1997 y 2002 de 31\% a 27\%, éstas se mantuvieron constantes en 52\% para la población indígena. En las áreas rurales, la extrema pobreza aumentó entre la población indígena (de 65\% a $72 \%$ ), pero disminuyó levemente entre los no indígenas (de 53\% a 52\%). La población no indígena empleada gana 1,127.00 bolivianos por mes, mientras que la población indígena empleada gana menos de la mitad de este monto (513.00 bolivianos). La población indígena tiene 3.7 años menos de escolaridad que la no indígena y la incidencia del trabajo infantil es cuatro veces más alta entre los niños indígenas que entre los no indígenas; en 2002, 31\% de los niños indígenas entre 9 y 11 años trabajaban, comparado con $8 \%$ de los niños no indígenas (véase Hall, s/f).

En Ecuador se estima que para 2001, 9.2\% de la población pertenecía a un hogar en el que al menos uno de los integrantes de la familia se autoidentificaba como indígena o hablaba una lengua indígena. En 1998, la población indígena tenía una tasa de pobreza de $87 \%$ para todo el grupo étnico y de $96 \%$ para aquellos que habitaban en las sierras rurales, comparado con $61 \%$ para la población no indígena. La extrema pobreza era de $56 \%$ para los indígenas y de $71 \%$ para los indígenas en las sierras rurales, lo cual se compara con el $25 \%$ de la población no indígena. Los ingresos laborales promedio entre la población indígena alcanzaban sólo el 55\% de los ingresos de trabajadores no indígenas. La población indígena tenía 2.7 
años menos de escolaridad que la no indígena y cerca del 24\% de la población indígena ni siquiera reportaba educación formal, comparado con el 5\% de la población no indígena. En el 2001 sólo 57\% de los niños indígenas entre 5 y 18 años asistieron a la escuela y no trabajaron, lo cual se compara con $73 \%$ de los niños no indígenas. La desnutrición crónica afectaba a un a 59\% de niños indígenas menores de 5 años, a diferencia del $26 \%$ de los niños no indígenas (véase Hall, s/f).

En Guatemala, cerca de un 39\% de la población se identifica como indígena. El nivel de pobreza de este sector cayó en un 14\% entre 1989 y 2000 llegando a 74\%, mientras que para los no indígenas el nivel de pobreza cayó en un 25\% Ilegando a 38\%. El diferencial de ingresos entre indígenas y no indígenas oscila entre $71 \%$ y $83 \%$ para las mujeres y entre $58 \%$ y $64 \%$ para los hombres. La población indígena tenía 2.8 años menos de escolaridad que la no indígena (véase Hall, s/f).

En México, cerca de un $11 \%$ de los hogares son indígenas y más de un $72 \%$ de este sector vive en áreas rurales. La incidencia de la pobreza extrema en 2002 fue 4.5 veces mayor en los municipios predominantemente indígenas, a diferencia de la proporción de 3.7 que había en 1992. En 2002, un individuo que vivía en un municipio donde del 10\% al $40 \%$ de la población era indígena, tenía un ingreso promedio equivalente al $46 \%$ del ingreso de un municipio no indígena. La población indígena tenía 3.3 años menos de escolaridad que la no indígena y la tasa de analfabetismo para la población indígena es de $24.6 \%$ en comparación al $6.4 \%$ para los no indígenas. La esperanza de vida es cuatro años menor en los municipios indígenas que en los no indígenas y la tasa de mortalidad es de 41 por cada 1000 nacidos vivos, en comparación a 24 por cada 1000 nacidos vivos (véase Hall, $s / f)$.

En Perú, entre un 25\% y un 48\% de los hogares pueden ser considerados indígenas. El límite inferior corresponde a los hogares en los cuales el 
jefe de hogar y/o su pareja utilizan una lengua indígena de manera más frecuente que castellano y el límite superior corresponde a todos los hogares en los que el jefe de hogar y/o su pareja tienen padres o abuelos que hayan tenido una lengua materna indígena. En el período 1994-2000 la pobreza entre los hogares indígenas aumentó de $62.3 \%$ a $62.8 \%$, mientras que en los hogares no indígenas aumentó de $40.1 \%$ a $43 \%$. La pobreza extrema disminuyó de $28.6 \%$ a $22.2 \%$ entre los hogares indígenas y de $10.9 \%$ a $9.5 \%$ entre los hogares no indígenas. Del total de los hogares pobres, $43 \%$ son indígenas. Del total de los hogares en extrema pobreza, 52\% son indígenas. En promedio, los miembros de hogares no indígenas ganan casi el doble que los hogares indígenas y La población indígena tenía 2.3 años menos de escolaridad que la no indígena (véase Hall, sf).

La marginación económica y social de los indígenas latinoamericanos, va sin embargo más allá de las cifras en las que se ve reflejada. Estas últimas muestran que las minorías étnicas tienen un peso importante en los cinco países referidos y que quienes forman parte de ellas ocupan los últimos peldaños de la sociedad, pero no alcanzan para retratar todas las esferas de exclusión a las que conducen.

\section{Ciudadanos de segunda}

Además de las carencias materiales, la mayoría de los indígenas latinoamericanos han sido sistemáticamente segregados de la vida social y política. Por lo general de manera encubierta y no asumida, la mentalidad racista se extiende a todo lo largo y ancho de América Latina; particularmente en los países en los que existe un pasado colonial fuerte, los indios representan una alteridad que se procesa ideológicamente a partir de criterios de superioridad racial y étnica (para la distinción entre ambos conceptos véase Gall, 2004). 
Generación tras generación comparte y transmite este tipo de ideología, imprimiéndole un sello estructural (véase Gall, 1998) que, en el corto plazo, tiene poco que ver con los conceptos de bondad y de maldad individuales. El imaginario racista, como lo bautiza Marta Casaus para el caso de Guatemala (véase Casaus, 1995) ha generado estereotipos que se reproducen a lo largo del tiempo ${ }^{3}$ y que todavía en los albores del siglo XXI, contribuyen a sobrevalorar negativamente las diferencias, convertidas en prejuicios atemporales, propias de las sociedades latinoamericanas (véase Gall, 1998, p. 149-150).

El racismo está en cierto sentido vinculado con la modernidad (para otro tipo de realidades históricas con las que también se asocia véase Gall, 1998); a diferencia de las sociedades previas que se estructuraban alrededor de la desigualdad, en las sociedades modernas la igualdad entre los individuos se establece por ley y su ausencia se convierte en un elemento a justificar (véase Wieviorka).

A ello habría que agregar que la conquista del territorio implicó un sometimiento de sus dueños originales; además del abuso físico, el control sobre la población indígena en la región llevó a construir una ideología discriminatoria, con la que se legitimaron los niveles de exclusión en los que desde entonces se ha visto sumergida.

Los indígenas latinoamericanos que por ley son iguales al resto de la población, por la vía de los hechos se han convertido en ciudadanos de segunda:

Más de la mitad de los países del continente reconocen el carácter pluralmente diverso de su Estado y garantizan los derechos de los indígenas en su Constitución y sus

3 En una encuesta que aplicó a integrantes de la oligarquía guatemalteca, Casaus encontró que los siete adjetivos más empleados para caracterizar al indígena fueron: sumiso, conformista, tradicional, moreno, bajo, haragán, introvertido (véanse Casaus, 1995, p. 201-210 y Pinto Soria, 1995, p. 32). 
leyes. Sin embargo, esto contrasta enormemente con la realidad que afronta la inmensa mayoría de los pueblos indígenas que se extienden desde Canadá por todo Centroamérica hasta el último extremo de Chile y Argentina, que a menudo reciben el trato de ciudadanos de segunda clase (véase Amnistía Internacional, 2002).

Para respaldar esta aseveración, Amnistía Internacional (Al) daba en 2002 ejemplos que se extienden a lo largo del subcontinente. Cuestiones relacionadas con la tierra y el medio ambiente, con la identidad cultural, con las agresiones contra defensores de los derechos humanos que trabajan con las comunidades, e inclusive violaciones de derechos básicos (homicidios, tortura y malos tratos, y abuso de la fuerza), son algunos de los indicadores de que la discriminación también llega al terreno de la política y que ello se manifiesta, entre otras cosas, en el tipo de aparato estatal que se ha construido (véase Amnistía Internacional, 2002).

Por mi parte, tiendo a coincidir con la evaluación de Al y a disentir del análisis más optimista que realiza el BM. Desde la óptica de este último, la existencia de partidos indígenas, de cláusulas constitucionales, y de programas de salud y de educación, permiten pensar que en el decenio 19942004, hubo "un aumento en la pujanza política de las comunidades" (véase Hall, sf).

Los propios autores del informe respectivo, dan cuenta de las contradicciones que genera su postura: "A pesar de que los pueblos indígenas de la región han aumentado su poder político y representación durante la última década, esto no se ha traducido en los resultados positivos - en términos de reducción de la pobreza- que hubiésemos esperado encontrar cuando comenzamos con esta investigación" (véase Hall, sf). Atrás de la supuesta paradoja, subyace la idea de que el ámbito político puede desligarse de un plano estructural con el que, en los hechos, se encuentra entrelazado. 
El error consiste en olvidar que la política como esfera diferenciada, tiene su origen en la necesidad de construir puntos de encuentro para superar los antagonismos que produce la interacción social. Es cierto que ante los niveles de contraste que caracterizan a las sociedades latinoamericanas, la tarea se antoja titánica, pero no por ello pierde su esencia. En lugar de descontextualizar el ámbito de las relaciones políticas para alcanzar metas que de otra forma se transforman en quimeras, hay que visualizarlo como un espacio público que, como tal, no puede abstraerse de las condiciones sociales en las que surge.

Desde tal perspectiva, la falta de participación y representación es consustancial a la dinámica excluyente que margina de los procesos nacionales a indígenas y a otras minorías (véase Hopenhayn, 2001, p.21). Si bien a partir de la presión ejercida desde la sociedad, los marcos legales han tendido a incorporar la heterogeneidad cultural, los alcances de las reformas constitucionales dependen de la voluntad para ponerlas en práctica.

De atenernos exclusivamente a las conquistas legales, muchos de los indígenas latinoamericanos gozarían de derechos que en la práctica les son ajenos. Tanto el Convenio 169 sobre pueblos indígenas y tribales en países independientes, como la Convención sobre todas las formas de discriminación racial, han sido ratificados por Bolivia, Ecuador, Guatemala, México y Perú. ${ }^{4}$ Asimismo, con excepción de Perú, estos países han reconocido constitucionalmente su condición pluricultural y multiétnica. ${ }^{5}$

No se trata de desestimar los avances; el que la ley incorpore la diferencia como principio normativo, es sin duda importante para ampliar el

\footnotetext{
4 Además de los países con mayor número de población indígena, ratificaron el Convenio Argentina, Colombia, Costa Rica, Honduras y Paraguay y la Convención Argentina, Bahamas, Barbados, Brasil, Chile, Colombia, Costa Rica, Cuba, El Salvador, Grenada, Guyana, Haití, Jamaica, Nicaragua, Panamá, República Dominicana, Santa Lucía, Saint Vincent y las Granadinas, Trinidad Tobago, Uruguay y Venezuela (véase Hopenhayn, 2001, pp. 28-29).

5 También lo han hecho Argentina, Colombia, Nicaragua y Paraguay (véase Hopenhayn, 2001, p. 31).
} 
espectro político. El tema es que, como he venido insistiendo, el ejercicio de la ciudadanía va más allá. Para que el marco legal se traduzca en formas de participación no necesariamente restringidas al individuo, ni derivadas de derechos políticos universales, todavía falta un trecho por recorrer.

El reconocimiento de la otredad ha correspondido, cuando se ha dado, a un campo discursivo que por lo general carece de correlato en las acciones estatales y/o sociales. Quienes por sus raíces e identidad cultural, su color de piel, su género, sus preferencias sexuales, religiosas o de otro tipo han luchado por ser incorporados a una cultura ciudadana que tiende a excluirlos, están conscientes de que la diferencia pesa (Kymlicka, 1997).

En los cinco países a los que aquí me he referido, han habido movilizaciones indígenas y reformas legales que tratan de responder a ellas, y aún así las minorías o mayorías étnicas siguen sin poder ejercer una ciudadanía plena. Los referentes sin embargo se han ido modificando y las transformaciones del Estado, el mercado y la sociedad civil en un mundo globalizado, le han dado un nuevo sesgo a la acción colectiva de los pueblos indígenas, particularmente en lo que se refiere a las mediaciones entre los planos comunal, nacional e internacional. Hoy en día, aunque sus estrategias políticas se estructuren de distintas formas, los movimientos y organizaciones indígenas tienden a expresarse y simbolizarse alrededor de códigos compartidos que les imprimen unidad discursiva (véase Bello, 2004).

Como parte de este escenario, la construcción de una ciudadanía diferenciada que en su eje recupere la cultura indígena, se ha convertido en una lucha por el reconocimiento de derechos específicos en el marco de los Estados nacionales. La identidad cultural se convierte en la base de la acción política, de las negociaciones con el Estado y de la presencia pública del actor-indígena en la sociedad (véase Bello, 2004).

Sobre todo durante las últimas décadas, en América Latina se ha incrementado el número de organizaciones políticas indígenas. Más que 
una recomposición de los grupos, ello corresponde a la entrada en escena de nuevas formas para canalizar las demandas en contra de la exclusión. Si antes las cuestiones relacionadas con las injusticias sociales eran las que daban cuerpo al discurso, el tránsito del siglo XX al XXI incorporó las que tienen que ver con la autonomía y la libre determinación y trasladó el acento al tema de la identidad, eliminando la subordinación de esta última a los intereses de las organizaciones de corte clasista (véase Navarro, 2003, pp. 109-110).

La etnicidad es una forma específica de identidad que se construye a partir de la interacción social; en su base hay algo más que las características observables de un grupo étnico y en ella confluyen el reconocimiento de pertenencia que cada uno hace de sí mismo, con el que los externos al grupo realizan. Es importante señalar su carácter dinámico y su capacidad para perdurar a través del tiempo, mediante procesos permanentes de adaptación, recomposición y redefinición que, justamente, son los que le permiten constituirse en referente de movilizaciones colectivas y de acciones políticas concretas (véase Velasco Cruz, 2003).

\section{A manera de conclusión}

La alteridad se ha colocado como punta de lanza para cuestionar una arena pública que parte de modelos homogeneizadores y dentro de la cual la diferencia tiene escasa o nula cabida. Al igual que los indígenas, otros actores han emergido al escenario sociopolítico latinoamericano defendiendo su derecho a la diversidad y ello nos obliga, entre otras cosas, a repensar los conceptos clásicos de democracia y ciudadanía, para vincularlos con un escenario que los ha desbordado.

Por lo pronto, a falta de categorizaciones adecuadas, algunos adjetivos ayudan para indicar que la condición de universalidad inherente a ambos 
conceptos no se cumple; aparecen en el horizonte ciudadanos de segunda y democracias que al necesitar ser acotadas, dan cuenta de todo lo que falta por hacer para erigir sociedades en las que el conjunto de la población ejerza sus obligaciones y derechos políticos.

Decidir si los regímenes que se extienden por el subcontinente corresponden a una democracia mínima (véase Bobbio, 1986), a una democracia delegativa (véase O’Donnell, 1992), a una democracia restringida (véase Lechner, 1999) o a cualquier otra caracterización que indique recortes del modelo original, escapa a los propósitos de las reflexiones que aquí se presentan. Más que adjetivarlo, interesa consignar el hecho histórico y, a partir de allí, señalar sus límites en términos de los actores que le dan forma y sentido.

Desde tal perspectiva, podría decirse que la debilidad institucional y la inexistencia de ciudadanías consolidadas, propicia que en los países del área se reproduzca la agregación inorgánica de poderes autoritarios y que, tras formas democráticas generales, prevalezcan instituciones poco democráticas (véase Oliver, 2000).

Además de las inercias que en sociedades como las nuestras dificultan el tránsito hacia estructuras políticas más incluyentes, los principios mismos de la democracia clásica enfrentan múltiples dificultades para validarse en un mundo globalizado y con características cuantitativa y cualitativamente distintas (véase Garretón, 1999).

Si bien las cortapisas para el ejercicio de la ciudadanía han tendido a desaparecer y mediante rituales periódicos se deposita la soberanía popular en representantes encargados de ejercerla, finalmente las decisiones públicas no surgen de una voluntad general expresada en votos. Este déficit democrático, se agudiza en los lugares en los que la vida institucional es más débil y donde a partir de las consideraciones hasta aquí expuestas, ni si quiera hay interés por simular una participación política formal. 
Los altos índices de abstencionismo y el desencanto que en términos generales han dejado las llamadas transiciones a la democracia en los países de la región, ${ }^{6}$ son dos de los indicadores de su poca incidencia para el día a día de buena parte de los latinoamericanos.

América Latina representa actualmente una extraordinaria paradoja. Por un lado, la región puede mostrar con gran orgullo más de dos décadas de gobiernos democráticos. Por otro, enfrenta una creciente crisis social. Se mantienen profundas desigualdades, existen serios niveles de pobreza, el crecimiento económico ha sido insuficiente y ha aumentado la insatisfacción ciudadana con esas democracias -expresada en muchos lugares por un extendido descontento popular- generando en algunos casos consecuencias desestabilizadoras (véase Programa, 2004, p. 11).

Así empieza el prólogo del informe sobre la democracia en la región que elaboró el Programa de las Naciones Unidas para el Desarrollo (PNUD) y aunque de acuerdo al mismo "no hay malestar con la democracia, pero hay malestar en la democracia" (véase Programa, 2004, p. 19), frente a tal descripción de lo que sucede en el área, uno se explica que casi la mitad de los latinoamericanos que en 2002 declararon preferir este régimen a cualquier otro, otorgaran el mismo valor al desarrollo económico (48.1\%), mientras que otro tanto similar (44.9\%) estuviese dispuesto a apoyar a un gobierno autoritario si resolvía los problemas económicos de su país (véase Programa, 2004, p. 137).

Por lo demás, habría que aclarar que lejos de desdeñar procesos que han costado múltiples esfuerzos y se han llevado vidas en el camino, las ideas aquí presentadas se enmarcan en un necesario reconocimiento de 
que la adopción de formas democráticas implica la apertura de espacios y que estos últimos son fruto de batallas emprendidas desde la sociedad.

Buscan también problematizar visiones optimistas que, aun si marcan las insuficiencias del camino andado, reducen los faltantes a una cuestión de gradualidad. Al concebir la ciudadanía como sumatoria de derechos y obligaciones que históricamente se han ido ampliando y continuarán haciéndolo, se olvida que para que unos y otras puedan ejercerse, es indispensable reducir las brechas que en términos de desigualdades económicas y sociales establecen accesos diferenciales a intercambios políticos cuya premisa básica es la igualdad entre sus participantes.

En la medida en la que las oportunidades de bienestar económico y social son tan dispares, la búsqueda de la homogeneidad se convierte en un factor indispensable para avanzar en los procesos democráticos. Desde tal perspectiva, el sentido ecualizador que subyace al modelo ciudadano debe mantenerse como una de las metas a alcanzar, pero este mismo sentido tendría que repensarse a la luz de las diversidades identitarias que pugnan por ser reconocidas e incorporadas en su alteridad.

Concluyo aclarando que si a lo largo de estas reflexiones retomé sólo algunos elementos de la experiencia indígena y en función de ellos intenté mostrar las dificultades para ciudadanizar mediante decreto, realidades donde privan relaciones económicas, sociales y culturales que, en más de un sentido, apuntan hacia direcciones contrarias para dicha ciudadanización, el universo de ejemplos no se limita a este sector, por el contrario, abarca a todos aquellos que dada su posición estructural, sus diversas formas de identidad cultural o cualquier otra variable que restrinja su participación en la arena pública, parecen convidados de piedra más que protagonistas de las emergencia democrática con la que América Latina despidió al siglo XX. 


\section{Referencias}

AMNISTÍA INTERNACIONAL. América: Los indígenas, ciudadanos de segunda clase en las tierras de sus antepasados. Comunicado de prensa del 11 de octubre de 2002, en http://www.es.amnesty.org/com/2002/com_11oct02.shtm

BANCO MUNDIAL, World Development Report 2000/2001. Attacking Poverty: Opportunity, Empowerment, and Security. Washington, D.C., Banco Mundial, 2000.

BANCO MUNDIAL, World Development Report 2002. Building Institutions for Market. Washington, D.C., Oxford University Press-Banco Mundial, 2001.

BANCO MUNDIAL, World Development Report 2003. Sustainable Development in a Dynamic World: Transforming Institutions, Growth, and Quality of Life. Washington, D.C., Oxford University Press-Banco Mundial, 2002.

BANCO MUNDIAL, World Development Report 2004. Making Services Work for Poor People. Washington, D.C., Oxford University Press-Banco Mundial, 2003.

BANCO MUNDIAL. World Development Report 2004. Making, A Better Investment Climate for Everyone. Washington, D.C., Oxford University PressBanco Mundial, 2004.

BELLO, Álvaro. Etnicidad y ciudadanía en América Latina. La acción colectiva de los pueblos indígenas. Naciones Unidas-CEPAL, 2004 (Libros de la CEPAL núm. 79).

BERMUDO, José Manuel. Ciudadanía e inmigración. In: Scripta Nova. Revista Electrónica de Geografía y Ciencias Sociales. Universidad de Barcelona, Núm. 94 (32), 1 de agosto de 2001 en http://www.ub.es/geocrit/sn-94-32.htm

BOBBIO, Norberto. El futuro de la democracia. Fondo de Cultura Económica, México, 1986.

CASAUS, Marta. Guatemala: racismo y linaje. San José, FLACSO-Programa Costa Rica, 1995.

FERRANTI, David de Guillermo; PERRY, Francisco Ferreira; WALTON, Michael Inequality in Latin America: Breaking with History?, Washington, D.C., Banco Mundial, 2004. 
GALL, Olivia, Los elementos histórico-estructurales del racismo en Chiapas. In: CASTELLANOS, Alicia y SANDOVAL, Juan Manuel (coords). Nación, racismo e identidad. México, Nuestro Tiempo, 1998 (colección Los grandes problemas nacionales).

GALL, Olivia. Identidad, exclusión y racismo: reflexiones teóricas y sobre México. Revista Mexicana de Sociología, año 66, núm. 2, abril-junio 2004.

GARRETÓN, Manuel. Democracia y democratización. México, Centro Investigaciones Interdisciplinarias en Ciencias y Humanidades-UNAM, 1999.

HALL, Gillete y HARRY A. Patrinos, Indigenous People, Poverty and Human Developmente in Latin America. 1994-2004. Hampshire, Banco Mundial, s/f. en

http://web.worldbank.org/WBSITE/EXTERNAL/BANCOMUNDIAL/EXTSPPAISES/ LACINSPANISHEXT/0, content MDK: $20505832 \sim$ menuPK: 508626 page PK:146736 piPK:226340 theSitePK:489669,00.htm

HOPENHAYN, Martín, CALDERÓN Fernando y OTTONE, Ernesto. Esa esquiva modernidad: desarrollo, ciudadanía y cultura en América Latina y el Caribe. Caracas, Venezuela, UNESCO-Nueva Sociedad, 1996.

HOPENHAYN, Martín y BELLO, Álvaro. Discriminación étnico-racial en América Latina y el Caribe. Santiago de Chile, CEPAL-ECLAC, 2001 (serie Políticas sociales núm. 47).

ILAQUICHE, Raúl, Ciudadanía y pueblos indígenas. Boletín ICCI-RIMAY. Publicación mensual del Instituto Científico de Culturas Indígenas. Quito, Ecuador, Año 3, No. 22, enero del 2001.

KYMLICKA, Hill. "El retorno del ciudadano. Una revisión de la producción reciente en la teoría de la ciudadanía". Ágora, Núm. 7, invierno de 1997.

LECHNER, Norbert. Estado, y sociedad en perspectiva democrática, 1999 en http://www.insumisos.com/Articulos/Estado\%20y \%20 Sociedad\%20en\% 20 una \%20perspectiva\%20democr\%C3\%A1tica.pdf

MACHINEA, José Luis, BÁRCENA, Alicia y LEÓN, Arturo (coord.). Objetivos de Desarrollo del Milenio: una mirada desde América Latina y el Caribe. Santiago de Chile, CEPAL, 2005. 
MARSHALL, T.H.. Ciudadanía y clase social. In: MARSHALL, T.H. y BOTTOMORE Tom. Ciudadanía y clase social. Madrid, Alianza, 1998 (El Libro Universitario. Sociología. Núm. 91).

NAVARRO, Marc, Sobre lo local y lo indígena: Hacia una nueva concepción de la ciudadanía en América Latina. Revista Europea de Estudios Latinoamericanos y del Caribe, núm. 75, octubre de 2003.

O'DONNELL, Guillermo. ¿Democracias Delegativas? Montevideo, Cuadernos del CLAEH, Segunda Serie, Año 17, núm. 61, 1992.

OLIVER, Lucio Fernando Costilla. América Latina: Entre la gobernabilidad la democracia y la nueva sociedad civil. Nómadas. Revista Crítica de Ciencias Sociales y Jurídicas, Universidad Complutense de Madrid, núm. 2, 2000.

PANORAMA SOCIAL DE AMÉRICA LATINA 2002-2003, Santiago de Chile, CEPALNaciones Unidas, 2003.

PINTO, Julio César Soria,. Población indígena, mestizaje y nación en Guatemala elementos históricos. Revista USAC, Universidad de San Carlos de Guatemala, núm 1, 1995.

PROGRAMA DE LAS NACIONES UNIDAS PARA EL DESARROLLO (PNUD), La democracia en América Latina. Hacia una democracia de ciudadanas y ciudadanos. Buenos Aires, Aguilar-Altea-Taurus-Alfaguara, 2004.

VELASCO CRUZ, Saúl, El movimiento indígena y la autonomía en México. MéxiCO, UNAM-UPN, 2003 (Colección Posgrado).

WIEVIORKA, Michel, Le racisme, une introduction. Paris, La Découverte-Poche, 1998. 
Sociologias, Porto Alegre, ano 9, no 18, jun./dez. 2007, p. 226-246

\section{Resumen}

Uno de los propósitos centrales de este trabajo, es cuestionar la posibilidad de construir intercambios políticos basados en modelos ciudadanos de participación, cuando las condiciones materiales en las que vive la mayoría de la gente, se contraponen a los principios básicos en los que debería descansar cualquier acuerdo de civilidad.

Palabras clave: pobreza, marginación, ciudadanía

Recebido: 14/12/2005

Aceite final: 16/06/06 